Western University

Scholarship@Western

Physical Therapy Publications

Physical Therapy School

$1-1-2013$

\title{
The bodily experience of cerebral palsy: a journey to self-awareness.
}

Laura K Brunton

Doreen J Bartlett

Follow this and additional works at: https://ir.lib.uwo.ca/ptpub

Part of the Physical Therapy Commons

Citation of this paper:

Brunton, L. K., \& Bartlett, D. J. (2013). The bodily experience of cerebral palsy: a journey to self-awareness. Disability and rehabilitation, 35(23), 1981-1990. 
1 The Bodily Experience of Cerebral Palsy: A Journey to Self-Awareness

4 Abstract

5 Purpose: The aim of the study was to describe the lived bodily experience of CP.

6 Method: This was a descriptive phenomenological inquiry. Ten participants were

7 interviewed about their bodily experiences of living with CP. Interviews were semi-

8 structured around pain and fatigue. Inductive thematic analysis was used to identify

9 themes.

10 Results: The bodily experience of CP centered on issues of fatigue and pain as a feeling

11 of muscle soreness. An overwhelming amount of the discussion on fatigue emphasized

12 the fatigue that occurs with walking and prolonged activity. Self-awareness of the

13 individuals' own bodies and adapting activity to continue to participate in various aspects

14 of their lives emerged as the most important theme. Some participants used strategies to

15 manage their pain or fatigue; other participants were not yet fully aware of how to

16 recognize signs of fatigue and/or how to adapt their activities.

17 Conclusions: Self-awareness appears to be an important process to be fostered by service

18 providers and parents. Specifically, encouraging youth with CP to be aware of their own

19 bodies and the effects (positive and negative) of activity on pain and fatigue should be

20 incorporated into transition programs as the individual becomes responsible for his or her

21 own health care needs. 


\section{Introduction}

2 "Cerebral palsy (CP) describes a group of permanent disorders of the

3 development of movement and posture, causing activity limitations, that are attributed to

4 non-progressive disturbances that occurred in the developing fetal or infant brain." p. 9 [1].

5 Although the injury to the brain is considered static, changes in functional status occur

6 over time as the manifestations of the lesion are ever-changing [2]. Change in the

7 appearance of $\mathrm{CP}$ over time can be caused by the development of the central nervous

8 system, evolution of motor patterns at both the reflex and voluntary levels, by motor

9 learning or by therapy [3] and by the natural history in terms of growth and development

10 of secondary impairments to the musculoskeletal system. Therapists and caregivers have

11 described a great deal of intra-individual variability of motor functioning for individual

12 children and adolescents with CP. This variability can be attributed to many reasons such

13 as stress, illness or anxiety; it can also be ascribed to fatigue that occurs during activities

14 of daily living including long distance ambulation or during periods of prolonged

15 standing [4].

16 A recent study identified fatigue, pain and joint deformities as the top three CP-

17 related impairments in adulthood that can interfere with activities of daily life [5]. Fatigue

18 has not been extensively studied in a population with $\mathrm{CP}$; the limited data available

19 demonstrates a lack of focus on functional tasks [6] and highlights the need to explore

20 fatigue from the perspectives of the individuals themselves. Pain however, has been

21 studied fairly extensively in the adult CP population and some literature is available on

22 adolescents' pain experiences. A high prevalence of chronic pain has been reported

23 among children and adolescents [7] [8]. Pain interferes with sleep, mobility and physical 
1 activities of daily living. It has also been suggested that there were greater impacts of

2 pain when the adolescents were up all day without rest, which could reflect fatigue that is

3 exacerbating pain [8]. Although there are quantitative data regarding prevalence of pain

4 and identification of painful sites, there is a dearth of information on the experience of

5 pain and how adolescents understand their pain. One study has examined how adults cope

6 with pain related to CP [9], however, there is a need to understand how adolescents

7 understand and experience pain in their everyday lives.

8 Similarly, very little information is available on how people with CP experience

9 their physical bodies. One study has explored the lived body in adults with $\mathrm{CP}$ and found

10 trends of a dys-appearing body, a not-appearing body as well as feelings of being

11 different and having restricted autonomy, among other themes [10]. Specific to the dys-

12 appearing body theme was the experience of pain, stiffness and fatigue. Fatigue was

13 described as being a new experience, emerging in adulthood that left them with no energy

14 [10]. One strategy that adults with CP used to participate in their daily lives included

15 planning and adapting activities [10]. It is interesting that the experience of fatigue

16 appeared sometime after childhood; however, the study did not explore how the

17 participants described fatigue as being a new experience or when specifically the fatigue

18 began. Another study was conducted to explore the experience of mobility in adolescents

19 with CP [11]. Consistent with the Sandstrom study [10], adolescents discussed similar

20 themes related to making choices, adapting to situations and constantly having to plan in

21 advance [11]. Because the mobility limitations discussed in the study by Palisano and

22 colleagues [11] are a result of having $\mathrm{CP}$, it is possible that these issues related to 
1 mobility could be related to the greater experience of living with $\mathrm{CP}$, and warrant further

2 study.

3 Finally, physical activity levels of youth and young adults with CP are lower than

4 their peers without disabilities $[12,13]$; however, it is not yet known how physical activity

5 relates to fatigue and pain experienced by these individuals. Some literature suggests that

6 low levels of physical activity may adversely affect adolescents living with CP as a result

7 of higher energy costs for movement [14], potentially leading to more fatigue

8 experienced by these individuals. Therefore, it is important to understand how these

9 factors may shape how adolescents and young adults experience their bodies in their

10 everyday world.

11 The purpose of this study is to have a client-centered account of fatigue and pain

12 that is experienced by adolescents and young adults living with CP using a

13 phenomenological approach [15]. Phenomenology is useful for studying the essence of an

14 experience and understanding how meaning is lived [15]. The goal of a

15 phenomenological study is to create an evocative text comprised of behaviours, actions

16 and meanings in the lifeworld, to understand the phenomena of interest [15]. This study is

17 the first to explore the experience and perceptions of muscle fatigue and pain directly

18 from adolescents and young adults with CP. It is particularly important to understand the

19 experience of fatigue and its relation to pain and physical activity that may result from

20 growth of the individual and to identify factors that shape the experience. The insights

21 gained will guide clinicians and care providers to improve therapy and services by

22 exploring, with the client, energy and time management approaches that will facilitate the

23 achievement of their desired levels of activity and participation. 


\section{Methods}

2 Participants

3 Adolescents (defined for this study as individuals aged 14 to 17 years) and young

4 adults (defined for this study as individuals aged 18 to 25 years) who were classified as

5 levels I to III on the Gross Motor Function Classification System (GMFCS) [16] and as

6 level I or II on the Communication Function Classification System (CFCS) [17] were

7 invited to participate from two children's treatment centres in southwestern Ontario.

8 Additionally, advertisements were placed in the newspaper at The University of Western

9 Ontario and in fitness centres around the city of London, Ontario. Finally, snowball

10 sampling was used to recruit interested adolescents and young adults through previous

11 participants. Descriptive information for each participant, including their pseudonym,

12 distribution of involvement, GMFCS and CFCS level, gender, educational or

13 employment status, and age can be found in Table 1.

Insert table 1 about here

\section{Data Collection Method}

16 Ethical approval was obtained from the Ethics Review Board at The University of

17 Western Ontario. One semi-structured interview was conducted with each participant in

18 the study. The interviews were approximately one hour in length, and conducted in

19 person by the main researcher (LKB) at a location convenient for the participant. Prior to

20 beginning the interview the primary author assessed each participant and classified their

21 communication and functional status according to the GMFCS and CFCS. During the

22 interview participants were first asked to describe their typical days (a probe for further

23 information included "How does your body feel as the day goes on?"), followed by 
1 asking them to describe a day in which they experienced fatigue and/or pain (probes

2 included what do you think caused the fatigue/pain, what did you do after you became

3 tired/sore?") and then more general questions about fatigue, pain and physical activity.

4 Data Collection Procedures

5 Demographic information (including distribution of involvement, sex, educational

6 or employment status and age) was collected by self-report and is presented in Table 1.

7 Interviews were audiotaped and transcribed verbatim. The researcher also used field

8 notes to identify areas to probe for further information to ensure participants' stories were

9 fully completed and explored to the extent the individual wished to share.

10 Analysis

11 There is no commonly agreed upon method underlying phenomenology; however, van

12 Manen [15] describes six methodological themes or activities to follow. van Manen's

13 approach to phenomenology was chosen as the methodological framework for this study

14 to ensure the results would be clinically relevant to clinicians and care providers who

15 work with individuals with $\mathrm{CP}$ and as a result of his perspectives on objectivity,

16 subjectivity and interpretation. Specifically, van Manen recognizes that objectivity and

17 subjectivity are not mutually exclusive and that the description can never be separated

18 from interpretation [15]. As a result, the authors acknowledge that the methods employed

19 in this study are interpretative in nature and that our preconceived notions and knowledge

20 about $\mathrm{CP}$ have contributed to the findings of the study.

21 Specifically, this study employed a hermeneutical approach to data analysis in

22 trying to understand the description and interpretation provided by the participants. Line-

23 by-line coding was performed in the NVivo 9 (QSR International, 2011) computer 
1 software program to identify any relevant text about the lived body within each transcript.

2 Subsequently, a thematic analysis approach was used, in that elements that were

3 continually apparent in the text were examined and interpreted as themes that allowed the

4 researcher to understand the meanings contained in those themes [15]. The researcher

5 returned to the field notes taken during the interviews at the time of analysis to reflect on

6 and add context to each interview, as the analysis was performed after all 10 interviews

7 were completed. Aspects of the interview that the participants put particular emphasis on

8 (either by repetition of the topic or through body language and/or intonation documented

9 in the researchers field notes) were considered to be meaningful to the participant and

10 captured as a code related to their lived bodies. Within each transcript the researcher

11 generated unique codes related to their experiences. The researcher then began to

12 combine codes and look for recurrence of similar codes across participants. Codes that

13 related to similar experiences of the lived body across participants were then aggregated

14 into larger themes. Themes were then graphically depicted to examine the inter-

15 relationships between themes related to the lived body. The analysis was guided by the 6

16 essential research activities described by van Manen [15] to ensure the researcher

17 remained committed to the text and that the analysis was a reflection of the important

18 aspects of the phenomena of interest. During the analysis the researcher continually

19 shifted focus by examining each individual participant's own meanings and looking for

20 convergence of meaning across all participants. The second author carried out an

21 independent coding and thematic analysis to confirm the relevance of the identified

22 themes. Participants were provided a written summary; a graphic depiction of the

23 commonly used terms and definitions of each theme identified in the analysis and were 
1 invited to provide their thoughts and comments regarding the analysis and themes

2 described.

\section{Results}

4 Ten individuals with $\mathrm{CP}$ between the ages of 15 and 24 participated in this study.

5 Although many participants discussed and expressed similar thoughts on each theme, for

6 the purposes of this manuscript only one or two quotes have been provided to illustrate

7 the different aspects of each theme. Many of the themes were inter-related and the

8 experience of living with $\mathrm{CP}$ was shaped by several components at once.

9 The major themes identified by the analysis can be seen in Figure 1. Each theme will

10 be described and explored in further detail. Each theme in Figure 1 overlaps with each of

11 the themes that were related to that specific theme. For example, the main theme of self-

12 awareness overlaps with the themes of balance, fatigue and variability and contains the

13 subthemes of planning, adaptation and restriction of activities.

Insert figure 1 about here

\section{Fatigue}

16 The bodily experience of $\mathrm{CP}$ centered on issues of fatigue and pain as a feeling of

17 muscle soreness. Despite questions posed by the researcher, other types of pain, not

18 related to muscle soreness, were not prevalent in the experiences of the participants in

19 this study. Only Danielle spoke about ongoing pain, primarily as a result of a surgical

20 procedure; the rest of the participants described pain that related to muscle soreness or

21 tiredness. A few participants explained what fatigue feels like to them. 
it's not that I completely collapse, but the sort of energy and strength that...that part of my body has is pretty well gone and so I can't really do any, like, strenuous activity." - Michael.

"Well, [pause] well if...if you tie a knot in the shoelace and then pull it and you can feel it getting tighter, that's what my muscles feel like if... when they're tired and in pain." - Danielle.

Some participants discussed fatiguing less when their full body weight was not required for the activity, for example, walking in water or swimming.

"Yeah, I would definitely have to say that [managing my whole body weight] does have an impact [on fatigue] 'cause if I'm swimming, I'll...I won't really fatigue as quickly as I would if I was say running or just having a long day at school. Mainly because...that pressure is off of my body and off of, sort of, my legs and my joints so that I don't reach that point of fatigue as quickly. So I would definitely say that being in a position where I don't need to fully manage my body weight and sort of maintain the movement of my whole system...is much easier on me in terms of fatigue and pain." - Michael.

An overwhelming amount of the discussion on fatigue emphasized the fatigue that occurs with walking, and the experience of fatigue primarily existed in the muscles of the legs. This was prevalent throughout all of the conversations and was mentioned throughout the discussion of other related topics. One example comes from Travis as he spoke about when he was most tired during an average day. 

14 individuals. activity.

"Usually I feel the most tired... at period four just because...there's a lot of walking for me to do, and by then in the day my legs are pretty tired because of the amount of walking ... that they've had to do." - Travis.

Many other participants reinforced the issue of fatigue with walking and prolonged

"Probably running, I would think that is the one major one. Or, just in general, like moving over long distances, so like running or walking...going up stairs, moving around the house, that doesn't really generate as much fatigue, but when I run or walk for longer periods of time then that is probably what generates the most fatigue for me." - Michael.

Many individuals talked about fatigue in a way that conveyed a finality of fatigue, speaking about it in terms and phrases like "my legs are done", "I'll collapse" and other analogies that that symbolized the intensity and large impact of fatigue for these

“They [muscles]...kind of feel like jelly just because you've been using all the muscles in your leg, so it's like...they feel like jelly. " - Travis.

"It would usually tingle for some reason and then my legs will just jelly and I will collapse, sometimes. " - Jennifer.

Fatigue was mentioned as a major consequence of activity, many participants talked about feeling fatigued and sore from muscle pain after a challenging day or a day that contained a great deal of physical activity.

"I find that, like, school trips... after I came back from [a] camp I was... ill because I was so tired. Like, just...walking... a lot of activities throughout the 
1 day...well my brain couldn't really keep up, so after that trip I...my brain kinda said

2 what... "we're done"...so it kinda...didn't know what to do...I think that's why I got ill

3 after." - Danielle.

$4 \quad$ Some participants talked about pushing themselves too hard with their physical 5 activities.

"There were some days where after a practice my back would hurt so much

$7 \quad$ where I'd try to get out of bed and I'd have trouble sitting up. It's like...the muscles

8 get restrictive at that point and they kind of respond saying "You haven't had enough

9 time yet. You shouldn't be going anywhere. Stop." - Nathan.

10 Although fatigue was a consequence of activity participants did not always view

11 physical activity as something that solely created fatigue. Many of the participants talked

12 about the benefits of being physically active on their endurance, energy level and even

13 potential preventative action against fatigue.

14 "Obviously...like, being more active and stuff although it might fatigue you

15 the day of and the day after, overall you're getting stronger, right? So it's...it gets

16 better and you get more energy as you keep doing stuff like that, so yeah, I think it 17 helps." - Chris.

18 "With cerebral palsy I can't really walk that far without getting tired. Like,

19 with fitness I, like I walk around, like...the fitness area and the first time I did it...I

20 could walk half of it and then have to take a break because I was winded. But

21 now... but since I've started fitness I can walk three or four times around." - Danielle.

22 The time of year and/or the weather was a factor that many participants discussed in

23 relation to the fatigue they experienced. Many participants expressed that winter weather 
1 compounded issues of fatigue and talked about other factors related to weather, such as

2 pressure changes and temperature. One participant spoke about fatigue and the weather

3 while relating it to his physical activity level.

$4 \quad$ "In the winter time, I would definitely say I am more fatigued, I'm a lot sorer,

5 I'm in a lot more sort of minor pain when I do physical activity...I'm not as active

6 during the winter months as I am during the summer, so I think that definitely has a

7 part to play, because in the summer time I feel more energized, I'm around, I'm

8 moving, I'm swimming, I'm going for runs. " - Michael.

10 Self-Awareness

11 Although fatigue was continuously discussed by all the participants with $\mathrm{CP}$, the

12 theme of self-awareness emerged from the analysis as the most essential theme related to

13 the bodily experience of CP. One component of this theme was becoming self-aware of

14 the limits of their physical bodies. In this theme participants spoke about knowing (or not

15 knowing) the limits of their bodies. One participant spoke about the experience of

16 learning his own limits of his body:

17 'I would say things to myself like 'What, are you soft?'... but 'I can go for another 10

18 minutes.' Then you'd reach that 10 minute mark and I'd feel like I had a little bit more

19 left in the tank, 'I could go for another 10 minutes'. Well I ended up going for about 42

20 minutes or whatever, I couldn't get off the treadmill...I had to be...carried off the

21 treadmill and, like, out of the gym and then picked up...I don't feel myself...getting

22 progressively tired...like I can coast then it just hits me all at once. Like, okay now I have 
1 no energy...I don't get like progressively fatigued, but...I know that about myself... and

2 through trial and error...I've been able to figure that out." - Geoff.

3 During the comparison across participants, the level of self-awareness that each

4 individual had achieved varied greatly. The level of self-awareness showed some relation

5 to age, such that the older participants in the study talked openly about knowing their

6 limitations and the consequences of activity, yet in some of the younger participants this

7 self-awareness was only starting to emerge. For example, Nathan, who was 19 years old,

8 speaks about not realizing his fatigue level until after activity is over.

9 "I feel it a lot more when I'm finished the day, when I actually realize how

10 much I've done and then I go sit down and it's like 'I'm going to be feeling that later

11 as opposed to now." - Nathan.

12 Interestingly, when asked about strategies to combat fatigue or to stop activity before

13 it reaches the point of having a consequence, this was something Nathan had not yet

14 considered.

15 "As far as strategies go...I'm not really sure I have one." - Nathan.

16 Travis who was also 19 years of age recognizes the fatigue in his body sometimes only

17 when it is too late and speaks about what can be done in the future, but has not yet

18 learned how to predict his fatigue.

19 "My legs are...my legs are done. After a good bike ride with my family, I can

20 definitely tell my legs are done...there are times... where I've had to stop and

21 actually...had to have one of my parents push me home because my legs were totally

22 done." - Travis. 
1 Travis was becoming aware of his limits and potential ways to mediate the effect of

2 fatigue on his body.

"[Using ice cream as motivation], it doesn't mean that my legs aren't going

4 to be tired, what it means is that even if my legs are getting... are tired, I'll still get

5 there, even if it means that my legs will be angry at me when I get... when I wake up

6 the next day." - Travis.

7 Michael was 18 years old but has had a lot of exposure to training and is very

8 physically active. This has been helpful to develop his sense of the limits of his body and

9 how to learn to recognize the signs of fatigue. He notes that there are times he did not

10 recognize that he had gone beyond the physical limits of his body, but that now he has

11 found a method or plan for ensuring that does not happen often.

12 "Really, when you reach that point where your body is...has completely

13 exhausted all of its energy... you have no energy left the morning after. Most of the day

14 I would probably either spend sitting or lying in bed or on the couch because...the

15 tiredness and the pain are still there from the day before or two days before depending

16 on how hard I pushed myself. So it is that...gradual sort of recovery period where you

17 have to take the time off to reach that neutral point again. But I've probably only

18 reached that point a couple of times, not very very often. 'Cause again I try to...the

19 best I can if I can reach a sort of closer point I'll try to take it a bit easier. ” - Michael.

20 Wade was 20 years old and he talked a great deal about being aware that he cannot do

21 things the way someone would expect him to, as well as ensuring that his own comfort is

22 important factor in determining the choices he makes. 
"So...yes. I guess it just comes down to adaptability and finding a different

2 way to do things, but it's about comfort too, you want to be comfortable, right." -

$3 \quad$ Wade.

4 Jennifer, who was 21 years of age, had become aware of the limits of her body.

5 Although she did not think she was directly planning her activities as a result, she

6 understood how to predict the occurrence of fatigue and techniques to manage this in her

7 daily life.

"Sometimes I can tell, sometimes I can tell the day before because of what

9 I've done that day. I know there are consequences of what I've done, so I can

10 sometimes predict...because I did this today, this is what I'm going to feel like

11 tomorrow, and I can get ready for it. So then I [am] able to plan my days, or...not

12 plan my days 'cause I'm not a big planner, but, like... sorta say well this is what it's

13 going to feel like and this...prepare myself more mentally, I guess, for it." - Jennifer.

14 Geoff was 24 years old and the participant with the most developed sense of self and

15 his limits. He talked a great deal about knowing his body and knowing his surroundings

16 and merging the two in order to enhance his functioning within his environment.

17 "So even though, my energy level is lower [now that I'm older], my pain

18 threshold is a little lower, recovery time is a little lower...but I have more of an

19 awareness now, so it kinda balances each other out, 'cause now I know what not to

20 do, how not to step, how to kinda plan a route... So that...it's kinda more of a

21 preplanning and an awareness of my own ability in conjunction with each other to get

22 from point A to point B without falling over." - Geoff. 
1 Although not all participants were fully self-aware, many participants spoke of

2 understanding the need to continue physical activity in relation to maintaining their

3 ability to ambulate.

4 “And plus I wanna ...practice walking." - Hillary.

5 "Just to maintain my muscles in my legs. Because I used my chair non-stop

6 probably for a year, and I noticed that my pants were too big in the back because I

7 had lost so much muscle and I didn't even realize...that happened, right? I don't want

8 to do that again." - Jennifer.

9 "In the last couple years, I've really sort of begun to understand the

10 importance of it [physical activity]. When I was very young I really didn't have any

11 mobility at all, I was confined to a wheelchair. From there it gradually progressed to

12 having ankle foot orthotics and a walker. And then, earlier in high school I eventually

13 developed the strength to just become totally independent...At that point...I realized

14 that if I didn't become physically active as part of my daily routine, I would lose

15 everything or at least backslide, so I...began taking that on." - Michael.

16 Anna spoke in her interview about not being very physical active, and relating this to

17 her experience of fatigue and her ability to walk now versus a time where she was more 18 active.

19 "Well I find now I kinda need to improve my walking, I don't find I can use

20 my walker as much as I used to. I find I get tired a lot more easily, probably because I

21 don't use it as often as I should, but...I use the wheelchair more, it's a lot faster, but I

22 do find it's inconvenient because...my parents have to take it and set it up, but I

23 wouldn't... be able to lift it up myself." - Anna. 
2 Planning, Adaptations and Restriction of Activities

3 There were several themes, other than fatigue, that were related to self-awareness.

4 Planning is a subtheme of self-awareness that was evident in most of the participants'

5 interviews; however, in some cases the participants did not realize they were planning

6 and making adaptations to their activities or daily lives to manage with fatigue and/or

7 pain that they experienced as a result of $\mathrm{CP}$.

8 "So I think it [fatigue] does play a part when I am planning the week, but

9 more subconsciously, like I'm not really fully thinking about it, I just sort of tell myself

10 when I get up, okay I'm pretty tired today, so let's take it easy. But I really don't think

11 about that if it makes any sense." - Michael.

12 When asked about having a routine, Anna spoke about needing to plan more in her life

13 to help her manage her fatigue and overall tiredness.

14 "I think I wouldn't be as tired [if I had more of a routine], and maybe would be

15 more active. I find that even ... over the years I think...I kind of decreased...I'm not as

16 healthy as I maybe used to be." - Anna.

17 Nathan spoke about researching his disability to be prepared for and to understand his 18 symptoms such as tremors.

19 "The more I know about my disability, or the more I've researched it, it was

20 a real...concern to me when I was...younger... I didn't know then I couldn't control

21 my shaking [when I get tired], but now I know that there's no use in trying to combat

22 it that just because it's natural and I know it's going to happen, it's not as big a

23 concern to me anymore." - Nathan. 
1 Adaptation is another subtheme of self-awareness. Participants often spoke about

2 making adaptations to their activities as a part of their everyday lives.

"You know, kids with CP we all...kinda want independence, you know, be

4 able to do our own thing and...find a way to get things done and...I find... a lot of it

5 comes down to... adaptability and there's always a way to do something...just...you

6 can't really do it... in the typical way, the way people are used to doing it." - Wade.

$7 \quad$ Planning and making adaptations were also related to each other. Chris talked about

8 finding new approaches to every day activities, activities that would not normally require

9 a plan for someone without $\mathrm{CP}$.

"You think of more than one way to do things, that's because you gotta find

11 the easier way and most effective way, so it's not ... too difficult and then doesn't take

12 too much time." - Chris.

13 Participants in the study employed many different strategies to adapt their activities to

14 manage fatigue. Several of the participants in the study expressed that they chose a

15 different method of mobility than they either usually employed or would like to use, in

16 order to manage fatigue, pain or other difficulties they experienced with their activities.

17 "[I] started using two [crutches] ...then I...could carry the bag and I could

18 last the whole day. So I guess it just depends on where you...kinda like... divert your

19 energy, right, 'cause my knees probably wouldn't last that long...I guess you find, a

20 different way of doing things." - Wade.

"Getting from class to class can be difficult...some days I use my walker, and

22 some days...I have a motorized scooter at home, which, has been a huge help even

23 though I was highly opposed to the idea originally. I'm very attached to my 
1 independence so... the idea of power mobility, I didn't want to become too self-reliant

$2 \quad$ on that sort of thing." - Nathan.

3 Some participants talked about using activity or stretching to keep muscles from

4 becoming too tight or from fatiguing from maintaining a static position.

"Like I'd try and stretch and stuff, and...like in a sense that pain is a good

6 thing...'cause I feel the muscles that can't build, I think, are because they're so tight

$7 \quad$ and so the more you keep them stretched out the more you can activate them and the

8 more they get stronger, and the less they tighten up, the more you use them." - Wade.

9 Michael talked about pacing his activity in order to manage his fatigue while running a

10 race.

11 "A couple of years ago me and Mom ran a 5 kilometre run back in the fall,

12 and I would run for part of it and then walk for part of it. So I would run for say, two

13 to three minutes, maybe less, and then I would walk for say a minute or two minutes.

14 Now I did that for probably close to two and a half, three kilometres, and then I

15 reached a point where to run, physically, the strength in my legs to push myself at that

16 speed just wasn't there. And I was, I was too tired, I had no energy in terms of my

17 actual leg energy to continue at that pace." - Michael.

18 One specific adaptation that was discussed by a large number of participants of this

19 study was restricting activity as a result of fatigue. Many participants talked about having

20 to restrict activity as a result of pain or fatigue.

21 "I know it's different with my age now too, but I used to go out in the winter

22 time and, say go tobogganing but I wouldn't even try to attempt that anymore. I was a

23 lot lighter and my Dad could carry me around a lot more when I was smaller, but, to 
1 do all that by myself it would be just too physically tiring, and...I'd be done for the

2 day after an hour of doing that kind of thing. " - Chris.

"So I think...wanting to do all these sports and wanting to be physically

4 active, knowing that I'm going to tire out quicker sort of almost hinders me to do those

5 things. So I think that could be one of the most worrying symptoms, to me, at least.

6 Just because there is that fear that if I do get so fearful of just tiring out that I

7 eventually just abandon the whole idea entirely and then become sedentary, which I

$8 \quad$ know is not going to help me at all." - Michael.

9 Interestingly, restriction of activity did not simply mean stopping or not pursuing an

10 activity because of fatigue or pain, Michael spoke about reducing the intensity of an

11 activity to manage fatigue.

12 "With me if I reach a point of fatigue where I realize, okay, if I go any harder

13 I'm probably not going to be able to get up stairs to sit down and actually recover. So

14 at that point, I'll pace myself, so I'll still keep working but not at the intensity I was,

15 so, I can at least finish the workout, but not overwork myself to the point of not being

16 able to recover afterwards." - Michael.

17 Similarly, Danielle spoke about changing her activities to compensate for pain.

18 "Well if, like, my back's hurting, I kind of avoid doing anything with it. I just

19 kind of stretch out muscles that are hurting, I...stay away from...working out muscles

20 that hurt, I just stretch them out instead of working them out. And that seems to be...

21 better than having them hurt." - Danielle. 
1 The link between self-awareness and restriction of activity can be explored by a quote

2 from Nathan, a participant who was just beginning to understand his own limits and

3 talked about these limits in terms of his activities.

$4 \quad$ "As I said before there's kind of a time delay on it where sometimes you feel

$5 \quad$ like you've got lots of energy and lots of reserve and all of a sudden it hits you and it's

6 like 'Oh man, I shouldn't have done all the stuff I did today' or 'I'm glad I got all this

7 stuff done, but now I'm not going to be able to do anything tomorrow because I'm so

8 worn down from yesterday' type thing. So, plan of action, a lot of times productivity

$9 \quad$ suffers as a result." - Nathan.

10 Rest was a major an adaptation made to accommodate fatigue or pain during activity

11 was prevalent and discussed by almost all of the participants. This discussion often

12 included talking about building in rest breaks, taking the chance to sit down or to lean on

13 something or someone to relieve fatigue and/or pain and to continue with their planned

14 activity. Allegorical and descriptive language was used by the participants to talk about

15 the need for rest, including words like "recharge", "recuperate" and "removes pressure"

16 conveying the overwhelming impact of fatigue on these individuals.

17 "I just sit down on my walker and take a rest." - Hillary.

18 "Just like... I was pretty done when I got here [to the interview], but like now

19 that I've been sitting down I'm starting to unwind a little bit...I'm still tired, but I

20 could go for a little while...I'm starting to recharge my batteries I guess." - Wade.

21 "Things like [dancing] are pretty strenuous too 'cause again, you're moving

22 in repetitive motions and...certain muscles aren't getting a break. So like I said....and

23 it's funny, I find that I...I look for areas to cheat, so if I'm out dancing...okay, closer 
1 to a wall perhaps, or a chair so I can kinda...every two minutes or whatever just lean

2 up against it, recharge the battery real quick and go again." - Geoff.

3 The participants also spoke about planning rest into their weeks, taking into account

4 all of their daily activities put together. Several participants spoke about using the

5 weekends for rest and the need to consider the additive action of fatigue over the week.

6 "It depends on what I've done that week. 'Cause definitely, if I'm going and

7 going and going and then I stop, then I feel it a lot more because I actually haven't

8 given my body a chance to recuperate." - Jennifer.

9 "On the weekend it gives me freedom to relax and...either get together with

10 somebody outside of school, or...take the time to kind of recharge for the next

11 Monday, I guess." - Nathan.

\section{Balance}

13 Balance was an additional concern that many of the participants spoke about in the

14 interviews. Balance was described in the study as something with a very fine line, the

15 participants used very descriptive words like "takes a swing" and "hanging by a thread"

16 reflecting the precarious nature of balance in $\mathrm{CP}$ and the variability of this attribute.

17 "I can go [standing] for a little while, problem is...I've literally

18 been...standing in front of the mirror for a little bit each morning trying to, just

19 stand...you know just trying to balance and stuff, 'cause that's a lot of my issue." -

20 Wade.

"But the biggest impediment for me would definitely be balance, I still have

22 difficulty...going down steps, two or more steps without assistance...I would have to,

23 like grab on to something or... and I'm not saying, like fully grab on, it could be 
1 something as simple as just, making contact with the person next to me to, kind of re-

2 establish my balance and then go. But then I'm bumping into everybody and that's not

3 the greatest thing either." - Geoff.

4 There were clear relationships between balance and self-awareness, noticeable in the 5 way individuals talked about their balance in relation to their bodies.

6 "I think I just know my body more now, I think and I can recognize the signs

7 and then prevent a fall, and I'm just a lot better at catching my balance now I think."

$8-$ Jennifer.

9 Further relationships were evident between the subthemes of self-awareness in the

10 way the participants planned, adapted and restricted their activity as a result of difficulties

11 with balance. Specifically, participants spoke about impairments in balance being

12 associated with their choices to participate in certain activities.

13 "Again, it depends on what I'm carrying, what I'm doing. Even simple

14 things like...I hate baking 'cause I don't like bending over... and sticking things in a

15 hot oven. But a stove or a barbeque no problem, I don't mind that at all 'cause it's

16 higher up and... and it's different. When I'm bent over I don't have my balance,

17 obviously isn't as great, so I'm always paranoid I'm going to fall." - Geoff.

18 'For me it's balance, so...yeah, as long as I'm holding onto something it's

19 usually alright. It's shaped who I am in a sense like in terms of what activities I do, I

20 mean, like kayaking versus hopscotch or tap dancing obviously I'm not going to be a

21 ballet dancer - it was one of my dreams when I was younger, so...I'm still you know,

22 kinda emotionally distressed over that. I looked really good in a tutu." - Wade. 
1 Balance and fatigue were also integrally linked in this study. Several participants

2 discussed fatiguing more when required to simply stand still or maintain their balance in

3 a static position, than they did during low-level activity.

$4 \quad$ "I get the most fatigued when I'm standing still. For example, like when I was

5 in...elementary school...I would feel more fatigued standing for the national anthem

6 and morning announcements, than I would for, like, outside running around at recess.

$7 \quad$ 'Cause it's that constant...pressure on your muscles and joints for an extended period

8 of time with no movement. Even in the movements themselves, by shifting the weight

9 and whatever, you're giving...other muscles kind of a breather." - Geoff.

10 "When I was in choir we had to stand up a lot because it's better for your

11 breathing, to stand up so you're not all cramped. And so we were standing for, like

12 two hours, which was a lot for me even. But that was... my breaking point." -

13 Jennifer.

14 Many participants also talked about balance being more compromised when they were 15 more fatigued.

16 "I would say in terms of my balance, my balance is usually affected by the 17 amount of activity I do, whether that's at home, or at the gym, just in general. If I do

18 work more, I become more off balance, I think my balance and my fatigue are very

19 much linked, so the more I work, the more tired I get, the more tired I get the more my

20 balance is affected." - Michael.

$21 \quad$ Variability

22 Variability was a theme many of the participants in CP discussed in a variety of ways. 
1 The participants in this study talked about not being able to predict the behavior of their

2 own muscles and many participants continued to state and re-state the unpredictability of

3 their own bodies.

4 "One of the things with CP is my balance... I don't know when my balance is

5 going to go - let's say if I'm on a walk and it's been long, I can tell that my balance is

6 going to take a swing, because after a long period of time my legs get tired and that's

7 usually when...I either have to hold on to a tree or I have to just tell my family that I

8 need to sit down because I'm going to lose my balance." - Travis.

9 Travis in particular spoke about how the unpredictable nature of fatigue further

10 restricted the activities he participated in.

11 "It's hard just because there are things that I can't do...if my youth group is

12 going on a hike, I can't do it just because with my disability it's hard...I have no clue

13 when my legs are going to give out on me and...I don't want to...slow them down

14 because...I understand that they're on a hike so...that's also fatigue and pain." -

15 Travis.

16 Some of the participants spoke about the amount of fatigue they experienced being

17 variable depending on their day and the activities they participated in.

18 "Depends what I'm doing, like, if I'm walking a lot during the day then my

19 body will fatigue faster." - Chris.

20 Geoff related some of the variability of fatigue with activity level to maintaining his

21 balance.

"It's just level of activity...I could be at a fatigue level at Monday at one

23 o'clock that I am today at 5. It just depends on what I'm doing all day. But fatigue is 
1 definitely a factor just because...my muscles are tired and ...if I was...less fatigued

2 then I would be more apt to trying, to catch myself, where... sometimes it's just like no

3 this isn't happening I'm going down so it's more of a protect your head, protect your

$4 \quad$ chest and...get up after." - Geoff.

5 Many participants talked about good and bad days, and that the experience of their

6 body differed depending on their day.

"I'll have good days and bad CP days, and on bad CP days I will try and not

8 walk as much because usually my muscles are really tight and it's just impossible to

9 actually get my feet to move the way I want them to. I'll drag them more which means

10 I trip over my shoes more and then I fall more and then...I don't know, it's just a

11 snowball of bad stuff." - Jennifer.

12 "Some days I wake up and I feel like "goodness, I want to fly". And some

13 days I still feel kinda lethargic at times, and...sometimes it's like "Okay, c'mon pick it

14 up, lets go, I'm late” or like "Damn it" you know "I'm slow today". - Wade.

15 Factors such as sleep, fatigue, activity level, balance and spasticity all played a role in

16 determining good days from bad days. Participants also spoke about knowing that after a

17 day where they felt good and maybe pushed themselves too hard, they had to incorporate

18 rest and recovery into the days that followed.

"Definitely my level of sleep the night before [determines whether it's a good

20 day or a bad day] because it just takes a lot more effort to do things if I'm tired. And

21 then I'm straining myself, I think, which causes more pain then." - Jennifer.

22 Although participants were asked to focus on the physical aspects of their bodies,

23 many participants could not fully separate the physical fatigue from mental fatigue and 
1 many felt it was an important associated factor that needed to be discussed. Many

2 participants talked about physical fatigue affecting mental functioning, and as a result

3 some participants used methods to limit fatigue in order to continue their academic

4 pursuits to their fullest capability.

$5 \quad$ "There are times that I get tired and that my brain turns off and then ... [my

6 language capabilities are] a little off centre, so it's like... when my brain's off I tend to

$7 \quad$ get a little bit hard." - Travis.

8 Motivation

9 On the other hand some participants spoke about being able to overcome or withstand

10 fatigue with motivation, or if the activity causing the fatigue was fun and enjoyable. In

11 addition, participants spoke about the benefits of exercise to their mental state, in spite of

12 how fatiguing the activity might be, the motivation to participate in sports or physical

13 activity allows them to deal with fatigue differently than fatigue they experience during

14 daily activities.

15 "I remember for the first two or three practices I really thought, why am I

16 going to all the trouble to come out here for, you know, three hours at a time after

17 school every day when I can be relaxing at home or working on an assignment. And

18 then I sort of reached this point where I realized that it was for me to prove to myself

19 that I could do these things. So it was almost like a turning point for me is to

20 understand that I can do these things and the reason why I haven't been doing them

21 for years is really beyond me and that I should have been starting much earlier." -

22 Michael. 
“[Playing wheelchair baseball ...it's giving me energy to...do what I want to

2 do. Not actually getting me tired, it's getting me...in the baseball spirit." - Hillary.

3 Increased Energy Expenditure and Time

4 Finally, participants spoke about the increased energy expenditure required of them

5 when participating in activities and the increased time required of them to complete

6 activities compared to their peers. Both of these factors were talked about by the

7 participants as "factual information" and were linked to fatigue. Particularly, individuals

8 in the study talked about slowing down their pace of activities to manage fatigue and

9 being accepting of the "fact" that activities required more time for successful completion.

10 "It's definitely... difficult because I think that cerebral palsy has this trait that

11 it definitely takes more energy out of you to do the same sort of physical exertion as it

$12 \quad$ would another person." - Nathan.

13 "I can work as hard as I want and I'll never...catch the slowest able bodied

14 guy just on my feet." - Wade.

15 Nathan spoke about the need to balance his desire to maintain his ability to walk and

16 his need for a mobility aid to facilitate his transfer between classes at college, because of

17 the energy expenditure and time that these transfers required of him.

18 "Just because I feel that if I become too self-reliant on it [powered mobility],

19 that's all I'm going to use and I'll be stuck to a chair for the majority of my adult life.

20 And if it weren't for surgery and various means of therapy I think I'd already be there

21 right now, but I've been lucky enough to retain some of my...function in my legs

22 and...I had been pushed for many years to switch to a wheelchair or powered mobility

23 and I originally didn't like the idea, but I admit getting around at school it would take 
much longer and it would be much more tiring if I didn't have that means of

2 transportation." - Nathan.

\section{Discussion}

4 It is clear from this phenomenological inquiry that fatigue is a major concern for

5 many individuals living with $\mathrm{CP}$. It is also clear that the experience of living with $\mathrm{CP}$ is

6 complicated and multifaceted. Many individuals experienced some common elements,

7 yet the variability in the experience of living with CP should be highlighted. Variability is

8 a widely used term in all areas of research in CP both in how the neurological deficit is

9 expressed (distribution of involvement, type of CP, secondary conditions that develop

10 etc.) as well as in the everyday experience of each individual. In order to manage fatigue

11 experienced on a daily basis, many of the individuals in this study found methods to

12 adapt or alter their activities, while other participants had not yet reached this point on

13 their journey to self-awareness.

14 In an ethnographic vignette of his own experience of living with CP, David Howe

$15[18]$ discussed very similar concepts around fatigue and balance. More interestingly

16 though, Howe describes being intensely aware and feeling his every movement; it is this

17 self-awareness that most resonates with the experience described in the current study.

18 Interestingly, although a potential limitation to this study is a lack of participants with

19 hemiplegia, the major theme and several subthemes resonates with Howe, who has

20 hemiplegia. Furthermore, a colleague at Western University who also has cerebral palsy,

21 a specifically hemiplegia, affirms themes of muscle soreness, balance and falling, along

22 with an interaction of balance and fatigue and an acute self-awareness of his body and

23 movements. 
Typically, adolescents and young adults are not required to plan their days or

2 weeks to combat physical symptoms such as fatigue; this is something that happens much

3 later in life for the general population. Notably, for individuals with CP gait efficiency,

4 gross motor function and performance have all been shown to slowly decline during

5 adolescence [19]. Although many individuals understand the importance of maintaining

6 participation in their daily activities, targeted therapy services for individuals with

7 disabilities are often limited during adolescence. Many of these factors and more may

8 combine and influence the experience of living with $\mathrm{CP}$ and the impact of many aspects

9 of the condition on the lives of these youth. When preparing for transition from pediatric

10 care, service providers typically encourage youth with $\mathrm{CP}$ to learn to manage their own

11 health care needs [20]. Self-awareness of their bodies and the impact of fatigue should be

12 fostered by service providers and included in clinical conversations about managing their

13 health care needs for the present and the future. Although it is not possible to generalize

14 the findings of this study to all individuals with $\mathrm{CP}$, service providers should consider the

15 individual's age and level of maturity when involving the youth in planning for future

16 care. This study highlights that each individual undergoes a specific and unique

17 development process and understanding each client's particular challenges with respect to

18 fatigue is important. Clinicians need to explore the role of exercise, adaptive equipment,

19 rest and other strategies for dealing with fatigue with their clients on an individual basis,

20 it is only then that they can help their client make well informed choices. Use of a

21 measurement tool to assess fatigue for individuals with $\mathrm{CP}$ could provide a starting point

22 to drive clinical conversations and determine individualized strategies for managing

23 fatigue. 
1 Self-advocacy is an important life skill to develop in order to navigate the adult

2 health care world, becoming self-aware is an important step to being able to initiate and

3 participate in conversations about their health care needs. Some authors have indicated

4 fatigue and inefficiency of gait as key factors contributing to loss of ambulation for

5 individuals with $\mathrm{CP}$ [21], therefore, learning to manage fatigue earlier may prevent some

6 loss of ambulatory skills for these individuals. A new measurement tool to assist with

7 assessing fatigue for youth and young adults with fatigue is currently being developed

8 and validated to facilitate clinical conversations about management of fatigue.

9

10 
1

2 Acknowledgments

3

4 We would like to thank Dr. Matthew Carter, Assistant Professor at Western University, 5 for his review of this manuscript and feedback regarding the resonance of the themes

6 with his personal experiences. This study was supported through a Canadian Doctoral

7 Student Scholarship awarded to L. Brunton from the Canadian Institutes of Health

8 Research. 
1

2 Declaration of Interest

3 The authors report no declarations of interest.

4 
2 References

3 1. Rosenbaum P, Paneth N, Leviton A, Goldstein M, Bax M, Damiano D, Dan B,

4 Jacobsson B. A report: The definition and classification of cerebral palsy April

5 2006. Developmental Medicine and Child Neurology 2007;S109:8-14.

6 2. Sanger TD, Delgado MR, Gaebler-Spira D, Hallett M, Mink JW, \& Task Force on

7 Childhood Motor Disorders. Classification and definition of disorders causing

$8 \quad$ hypertonia in childhood. Pediatrics 2003;111(1):e89-97.

9 3. Rosenbaum PL, Russell DJ, Cadman DT, Gowland C, Jarvis S, Hardy S. (1990).

10 Issues in measuring change in motor function in children with cerebral palsy: A

11 special communication. Physical Therapy 1990;70(2):125-131.

12 4. Bjornson K, Graubert C, McLaughlin J, Kerfeld C, Clark E. Test-retest reliability

13 of the gross motor function measure in children with cerebral palsy. Physical and

14 Occupational Therapy in Pediatrics 1998;18(2):51-61.

15 5. Hilberink SR, Roebroeck ME, Nieuwstraten W, Jalink L, Verheijden JMA, Stam

16 HJ. Health issues in young adults with cerebral palsy: Towards a life-span

17 perspective. Journal of Rehabilitation Medicine 2007;39:605-611.

18 6. Brunton LK, Rice CL. Fatigue in cerebral palsy: A critical review. Developmental

$19 \quad$ Neurorehabilitation 2012;15(1):54-62.

20 7. Doralp S, Bartlett DJ. The prevalence, distribution and effect of pain among

21 adolescents with cerebral palsy. Pediatric Physical Therapy 2010;22:26-33.

22 8. Engel JM, Petrina TJ, Dudgeon BJ, McKearnan KA. Cerebral palsy and chronic

23 pain: A descriptive study of children and adolescents. Physical and Occupational

24 Therapy in Pediatrics, 2005;25(4):73-84. 
19 . Engel JM, Jensen MP, Schwartz L. Coping with chronic pain associated with

2 cerebral palsy. Occupational Therapy International 2006;13(4):224-233.

3 10. Sandstrom K. The lived body - experiences from adults with cerebral palsy.

$4 \quad$ Clinical Rehabilitation 2007;21:432-441.

5 11. Palisano RJ, Shimmel LJ, Stewart D, Lawless JJ, Rosenbaum PL, Russell DJ.

6 Mobility experiences of adolescents with cerebral palsy. Physical \& Occupational

$7 \quad$ Therapy in Pediatrics 2009;29(2):133-153.

8 12. Maher CA, Williams MT, Olds T, Lane AE. Physical and sedentary activity in

9 adolescents with cerebral palsy. Developmental Medicine and Child Neurology

$10 \quad 2007 ; 49: 450-457$.

11 13. Brunton LK, Bartlett, DJ. Description of exercise participation of adolescents

12 with cerebral palsy across a 4-year period. Pediatric Physical Therapy

$13 \quad 2010 ; 22: 180-188$.

14 14. Maltais DB, Pierrynowksi MR, Galea VA, Bar-Or O. Physical activity level is

15 associated with the $\mathrm{O} 2$ cost of walking in cerebral palsy. Medicine and Sciences

16 in Sports and Exercise 2005;37(3):347-53.

17 15. van Manen M. Researching lived experience: Human science for an action

18 sensitive pedagogy. London, Canada: The Althouse Press; 1997.

19 16. Palisano RJ, Rosenbaum PL, Bartlett DJ, Livingston MH. Content validity of the

20 expanded and revised gross motor function classification system. Developmental

$21 \quad$ Medicine and Child Neurology 2008;50:744-50.

22 17. Hidecker MJC, Paneth N, Rosenbaum P, Kent RD, Lillie J, Johnson B, Chester K.

23 Developing a classification tool of functional communication in children with 
cerebral palsy. Developmental Medicine and Child Neurology 2008;50(Suppl.4):

43.

18. Howe DP. Reflexive ethnography, impairment and the pub. Leisure Studies 2009;28(4):489-96.

19. Kerr C, McDowell B, Parkes J, Stevenson M, Cosgrove AP. Age-related changes in energy efficiency of gait, activity and participation in children with cerebral palsy. Developmental Medicine and Child Neurology 2011;53:61-7. approach. Physical and Occupational Therapy in Pediatrics 2006;26(4):47-62.

10 21. Mockford M, Caulton JM. The pathophysiological basis of weakness in children

11 with cerebral palsy. Pediatric Physical Therapy 2010;22:222-33. 
Table 1 - Individual Participant Characteristics

\begin{tabular}{|l|l|l|l|l|l|l|}
\hline Participant & $\begin{array}{l}\text { Distribution of } \\
\text { Involvement }\end{array}$ & $\begin{array}{l}\text { GMFCS } \\
\text { Level }\end{array}$ & $\begin{array}{l}\text { CFCS } \\
\text { Level }\end{array}$ & Sex & $\begin{array}{l}\text { Educational/ } \\
\text { Employment Status }\end{array}$ & Age \\
\hline Wade & Diplegia & II & I & Male & Full-time Student & 20 \\
\hline Chris & Diplegia & II & I & Male & Full-time Student & 16 \\
\hline Geoff & Diplegia & II & I & Male & Full-time Student & 24 \\
\hline Anna & Quadriplegia & II & I & Female & Unemployed & 20 \\
\hline Danielle & Triplegia & II & I & Female & Full-time Student & 19 \\
\hline Travis & Diplegia & II & I & Male & Full-time Student & 19 \\
\hline Nathan & Diplegia & III & I & Male & Full-time Student & 19 \\
\hline Hillary & Diplegia & III & II & Female & Full-time Student & 15 \\
\hline Jennifer & Diplegia & III & I & Female & Full-time Student & 21 \\
\hline Michael & Diplegia & I & I & Male & Full-time Student & 19 \\
\hline
\end{tabular}


1 Figure 1 - Graphical representation of major themes and relationships between themes.

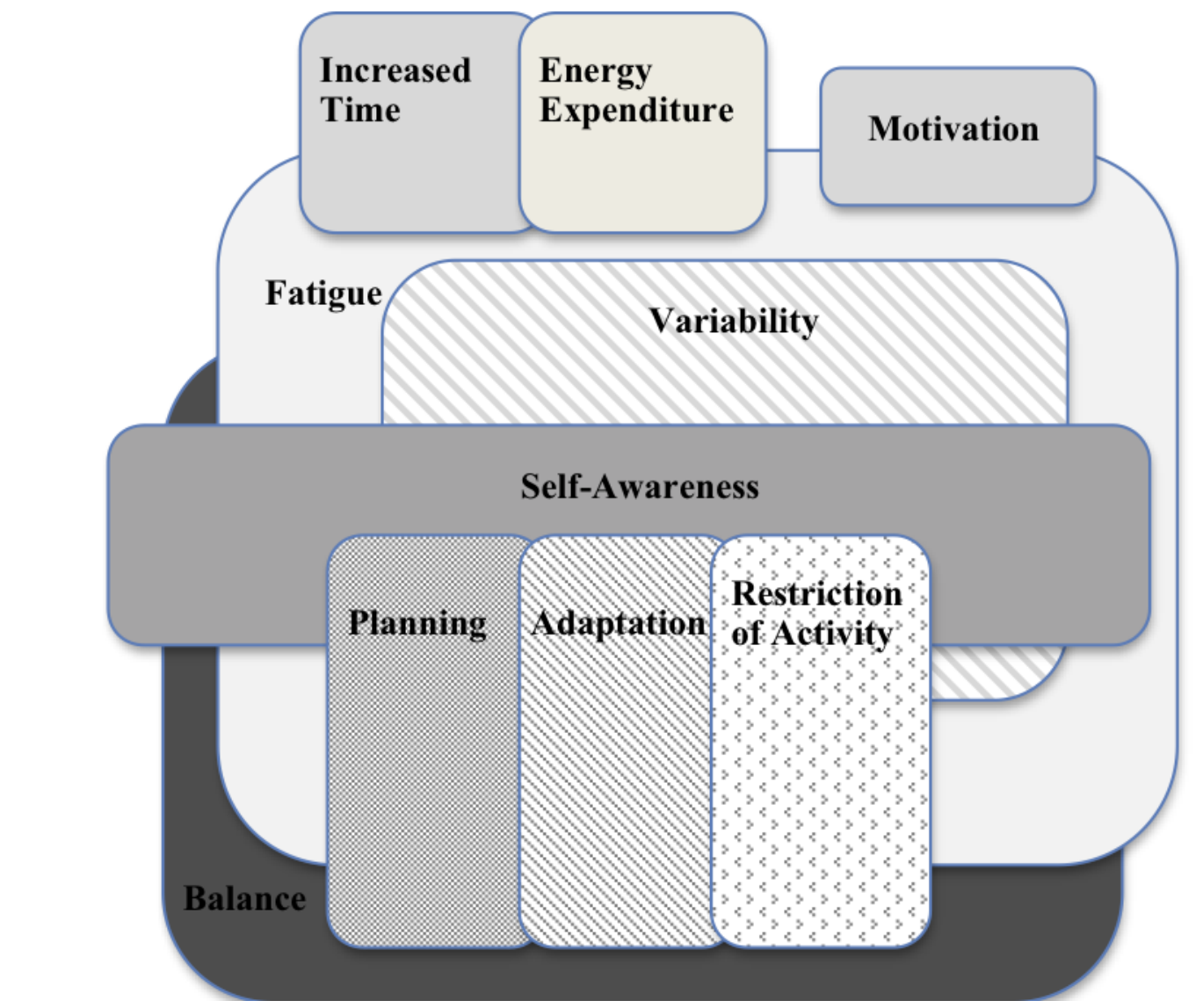

